\title{
Human behaviour should be recorded in (dis)comfort research
}

\author{
M. Smulders* and P. Vink \\ Faculty of Industrial Design Engineering, Delft University of Technology, Delft, The Netherlands \\ ORCID: 0000-0001-9957-0991 (M. Smulders); ORCID: 0000-0001-9985-3369 (P. Vink)
}

\begin{abstract}
Dis)comfort research that has no information on behaviour of the participants can be considered as incomplete, as major influencing factors could be missed. For (dis)comfort research it is important to capture factors such as context, task/activity, posture, movement, (distracting) stimuli and time, as these factors have influence on the experienced (dis)comfort. Recording the behaviour allows for better evaluation of and comparison between studies, contributing to an increase of scientific knowledge on (dis)comfort.
\end{abstract}

Keywords: Context, activity, posture, movement, stimuli

\section{Introduction}

"Research that has no information on behaviour of the participants can be considered as incomplete as major influencing factors could be missed." This might sound like a bold statement, but there is evidence that the way humans behave during and prior to an experiment does influence the outcomes. For example, a straight spine in the sagittal plane is sometimes considered ideal for sleeping [1] (see Fig. 1), but the actual behaviour of humans in bed asks for many other ways of support as shown in Fig. 2, as humans have different preferred postures [2] and change posture between 20-40 times a night [1, 3, 4].

Research in this special issue of WORK on comfort demonstrates that as well. To mention some examples: Califano et al. [5] stated that task-related upper limb activities are one of the most influential factors in the overall comfort perception while sitting at a school desk, which shows the importance of recording behaviour influenced by the task. Fiorillo et al. [6] studied comfort of library chairs, where com-

\footnotetext{
*Address for correspondence: M. Smulders, Faculty of Industrial Design Engineering, Delft University of Technology, Landbergstraat 15, 2628CE Delft, The Netherlands. E-mail: m.smulders@tudelft.nl.
}

fort decreased over time. So, if you have a searching task in the library for an extensive duration, comfort reduces over time. Sharafkhani et al. [7] showed that when aircraft passengers assume a posture with the head rotated more forward, the comfort decreases faster than when having a more upright head, which is in line with previous findings of Smulders et al. [8]. Maybe using a smart-phone with the head flexed would result in less comfort than watching the In Flight Entertainment (IFE) screen while seated in an aircraft seat. Also in an airplane, Torkashvand et al. [9] asked flight attendants what activities passengers would give a low comfort rating in economy class; sleeping and relaxing were awarded the lowest comfort ratings. Passengers reported the same activities as least comfortable in economy class in a study by Bouwens et al. [10], who found a statistically significant difference in importance of comfort influencing factors for sleeping and watching IFE. Probably sleeping upright or with limited recline is not so comfortable, as sleep efficiency is also lower [11]. Additionally, other factors than posture influence comfort. Moertl et al. [12] showed in this special issue that under a higher workload, participants reported higher acoustic discomfort for the same sounds than under a lower workload. 

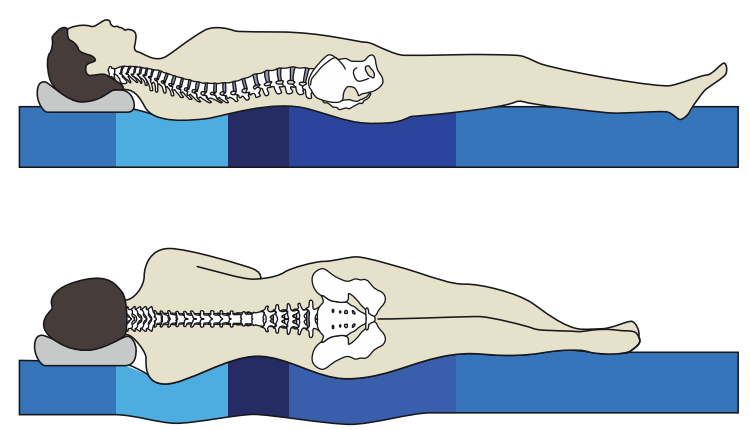

Fig. 1. Example of supine and lateral support for a 'straight' back. From Smulders [2].

\section{Theoretical explanation}

The reason why behaviour influences (dis)comfort is that the experience of (dis)comfort has various behaviour related sources. This experience is partly due to ourselves (e.g. physicality and state of mind), our history and expectations (e.g. previous experiences) and the environment (e.g. stimuli) [13]. As it is not the product itself that is comfortable, comfort experience depends on the way the user interacts with the product [14]. If we decide to investigate ourselves what our current comfort status is, we will experience some form of (dis)comfort. So the experience of (dis)comfort can also be initiated independent of the environment.

Of course the environmental context plays a role as well $[15,16]$. In most experiments something is changed in the environment and the effect on the human is tested. In the definition of comfort by Vink and Hallbeck [17] this is clear: "comfort is seen as a pleasant state or relaxed feeling of a human being in reaction to its environment". Whatever the start of the experience of comfort, there is always an initiator, which could be the human or a change in the environment. Then there is a weighing process of all sensory input, after which an unconscious or conscious decision is made on what the level of experienced comfort is. In the sensory input behaviour plays a role, as it determines what the receptors sense, but it can also play a role in the weighing, as distraction could change the (dis)comfort perception and certain actions/context influence the impact of stimuli. In the next paragraphs some examples of these principles will be explained.

\subsection{Context and activity versus (dis)comfort}

In (dis)comfort research it is important to state context and experimental activities, as these have impact on the conducted postures, movement, and the influence of perceived stimuli. E.g. Bouwens et al. [10] showed that context and activity impact the influence of sensory stimuli - such as posture restrictions, noise, smell, climate, vibration and light - on perceived comfort. Smulders et al. [18] show that different activities in a business class aircraft seat result in different postures and thereby do influence comfort. Groenesteijn et al. [19] show this in office seats, Groenesteijn et al. [20] in train seats and Kamp et al. [21] in semi-public spaces and in transit. As shown by Ahmadpour et al. [22], also proximity to other people influences the comfort experience (see Fig. 3).
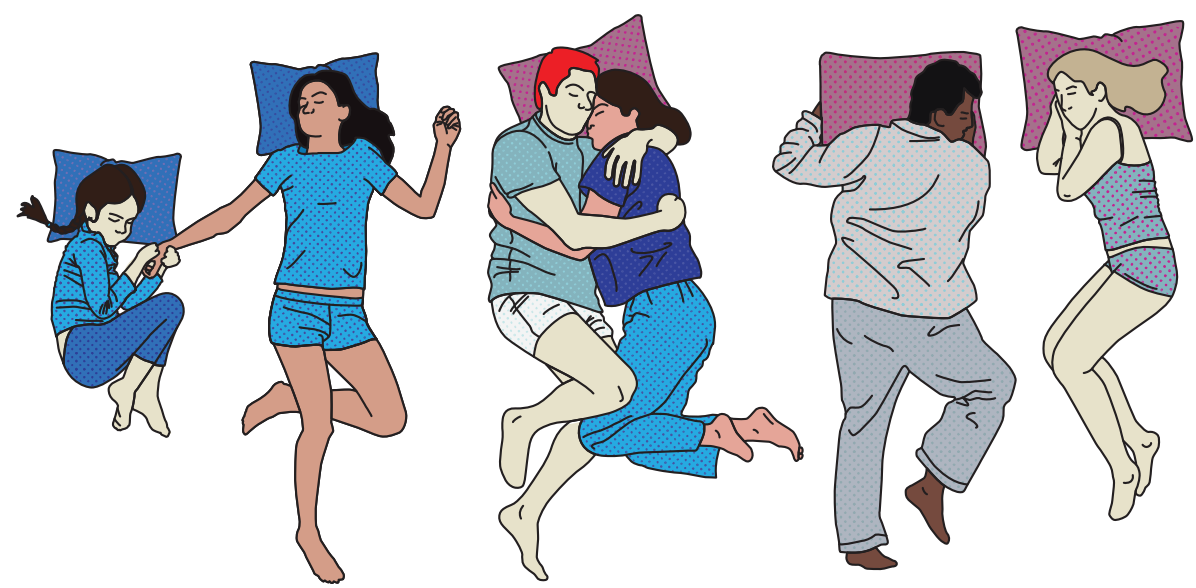

Fig. 2. Example of the importance of investigating human behaviour in e.g. sleep ergonomics, as people assume different postures and move during sleep. Illustration by Allison Pottasch and Maxim Smulders. 


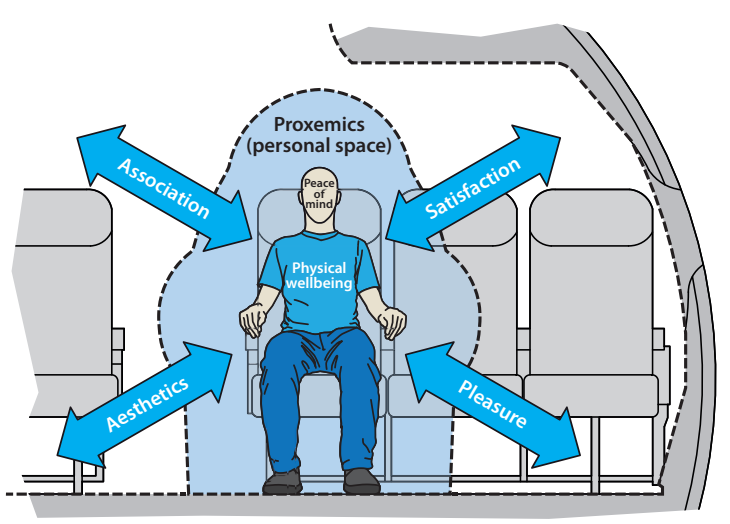

Fig. 3. Example of the relation between context features and passenger comfort. From Ahmadpour et al. [42].

\subsection{Posture versus (dis)comfort}

In (dis)comfort research it is important to state the observed postures, as they have impact on perceived (dis)comfort. E.g. Kilincsoy [23] recorded the comfort of passengers in the rear seat of a car and showed that the upright posture had lower comfort scores than the more relaxed postures in some parts of the body. Apostolico et al. [24] showed that the more neutral the posture is, the more comfortable the posture is rated (see Fig. 4). Smulders et al. [8] suggest that humans tend to seek for a neutral posture with minimal muscle strain, minimal use of energy and minimal discomfort.

\subsection{Movement versus (dis) comfort}

In (dis)comfort research it is important to state movement observations, as they have impact on the

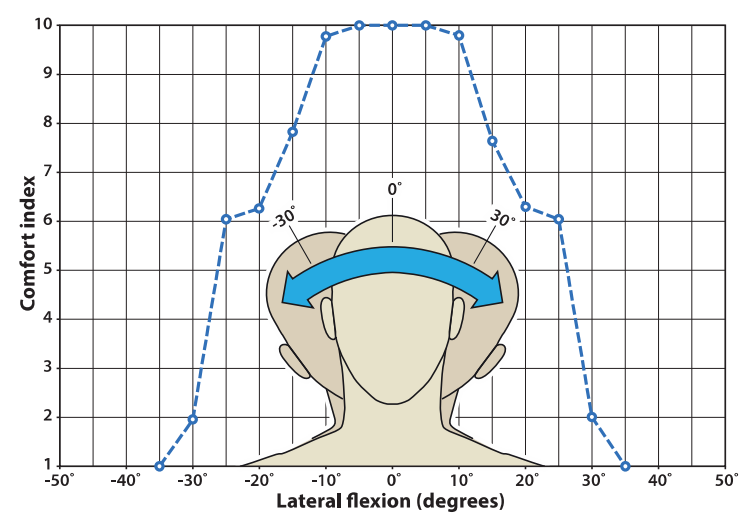

Fig. 4. Relation between head angle (posture) and comfort, showing the comfort rating (10-point scale) for degrees of lateral flexion of the head $(n=100)$. From Naddeo [43].

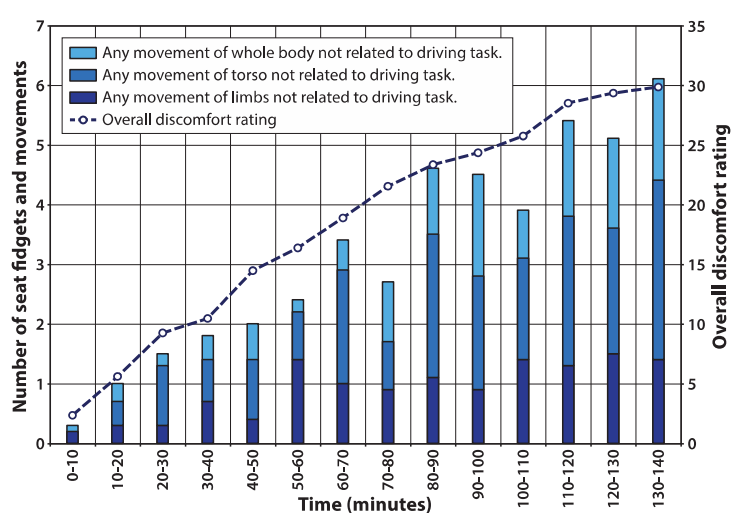

Fig. 5. Example of the relation of movement and discomfort (35point scale), showing the mean overall discomfort rating and number of seat fidgets and movements (SFMs) against time for all participants $(n=10)$. From Sammonds et al. [25].

perceived (dis)comfort. E.g. Sammonds et al. [25] show there is a correlation between movements and perceived discomfort, where more movement is correlated with more perceived discomfort (see Fig. 5). Similar results were observed by Le et al. [26] and Bouwens et al. [27]. Hiemstra-van Mastrigt et al. [28] and Bouwens et al. [29] showed that stimulating inseat movement improved comfort. Van Veen et al. [30] showed that a slow passive movement of the backrest and seat pan that is hardly noticeable has a positive impact on comfort as well. For an active movement system, Franz et al. [31] showed that a massage system in the backrest increased comfort and reduced muscle activity in the neck. Also Van Dieën et al. [32] suggest that dynamic office chairs offer a potential advantage over fixed chairs, as dynamic seats lower spinal shrinkage.

\subsection{Previous conditions versus (dis)comfort}

In (dis)comfort research it is important to state the pre-test conditions, as they might have impact on perceived (dis)comfort. E.g. Van Veen and Vink [33] showed that prior seating conditions (a hard or soft seat surface) significantly influence the experienced seat comfort, as sitting on a hard surface in the precondition made the next seat feel softer. Roelofsen [34] described that when one is exposed to a broader range of temperatures during their lifetime, the range of temperatures one considers comfortable is broader as well. That said, humans are bad at noticing gradual changes over time [35]. Also participant expectations play a role, as shown in an experiment by Naddeo et al. [36] where participants rated a mattress of which they were told that it was very expensive as more 


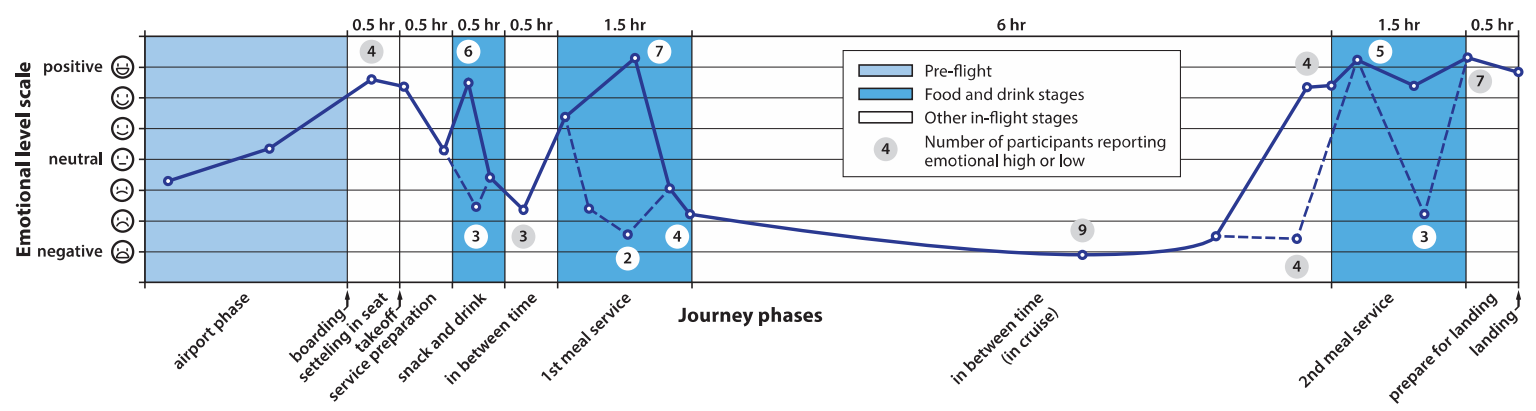

Fig. 6. Example of impact of stimuli on emotional level (7-point scale), showing the emotional time line of passengers during flight $(n=9)$. The solid line shows the overall emotion level participants have during different stages of the flight and the dashed line shows the outliers. The numbers in the bubbles represent the number of participants that reported their emotions similarly. From Bouwens et al. [38].

comfortable than the exact same mattress of which they were told that it was cheap. Participants' initial comfort expectations can also contradict the actual experienced comfort. Bouwens et al. [27] show this in travel pillows, where an 'embrace sleep collar' (which restricts head movement) was visually rated least comfortable, but rated as most comfortable after actual use.

\section{5. (Distracting) stimuli versus (dis)comfort}

In (dis)comfort research it is important to state the stimuli, as they might have impact on perceived (dis)comfort. E.g. Hiemstra-van Mastrigt et al. [37] and Bouwens et al. [38] showed that distractions such as meal services (see Fig. 6) and walking breaks during long-haul flights lowered the experienced discomfort and increased passengers' positive emotional level. Lewis et al. [39] showed that with a VR entertainment system, passengers can be distracted from discomfort caused by a lack of knee space. In addition, Hiemstra-van Mastrigt et al. [37] showed that interaction with other people could also distract from discomfort.

\subsection{Time versus (dis)comfort}

In (dis)comfort research it is important to state the duration, as time has impact on perceived (dis) comfort. E.g. Vink et al. [40] show in their literature comparison that generally comfort decreases over time (see Fig. 7) and discomfort increases (see Fig. 5) when conducting the same activity. Being aware of 'the end' of an activity will influence the comfort perception as well. Prolonged sitting in an aircraft and being aware that the landing procedure will start soon, can actually increase comfort (see Fig. 8). Thus, participants being aware of the time and duration of an

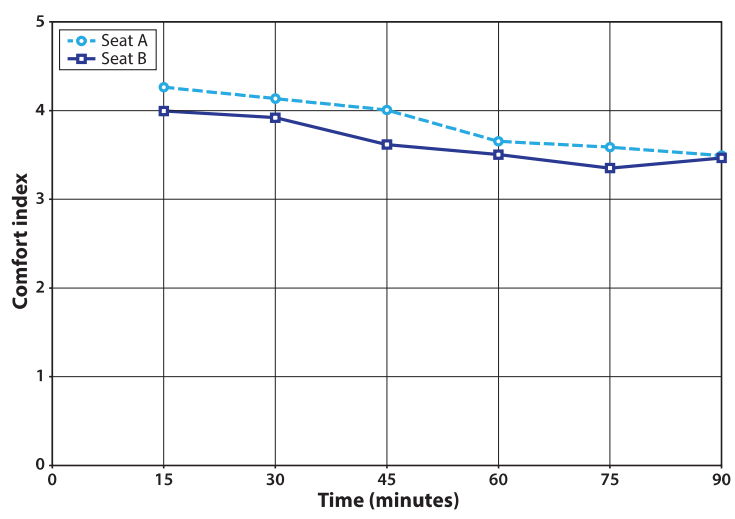

Fig. 7. Example of change of comfort (6-point scale) over time of business class passenger in two (A: reference seat, B: seat based on the human contour) different business class seats $(n=20)$. From Smulders et al. [18].

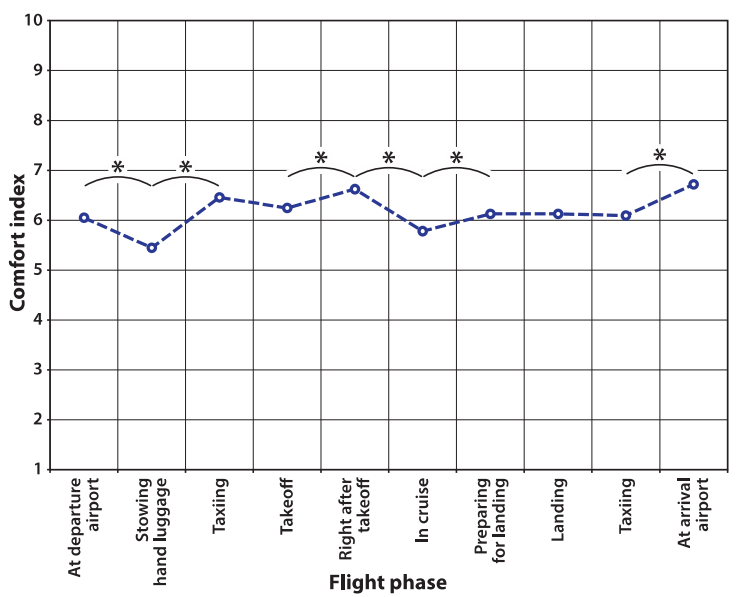

Fig. 8. Example of change of comfort (10-point scale) over time $(n=149)$. From De Lille et al. [44] and Bouwens et al. [38].

activity can actually influence test results. E.g. Sammonds et al. [41] discuss that drivers adjust their behaviour over time to cope with discomfort. 


\section{Conclusion}

It is important in (dis)comfort research to indicate what participants did before participating in the test (prior activities), how they move/behave during the test, what postures they assume and whether there are stimuli used that distract or influence the behaviour. In addition, the duration of activities and stimuli (and the fact of the participant being aware or not of time and the end of activities/stimuli) should be captured as well, as these all have impact on the experienced (dis)comfort. Reporting these factors allows for better evaluation and comparison of comfort research results, which should contribute to an increase of scientific knowledge on (dis)comfort.

\section{Acknowledgments}

The authors would like to thank Allison Pottasch for allowing to use one of her great illustrations, and prof. Alessandro Naddeo, prof. Neil Mansfield and dr. Naseem Ahmadpour for allowing us to use their graphs in this publication. In addition, the authors would like to acknowledge the contributions of the cited authors to the scientific field on comfort.

\section{Conflict of interest}

\section{None to report.}

\section{References}

[1] Haex B. Back and bed: ergonomic aspects of sleeping. Florida, USA: CRC press; 2004.

[2] Smulders M. Flex and relax: an exploration on headrest design for sleeping and watching IFE in premium aircraft seats [Master thesis]. Delft: Delft University of Technology; 2018.

[3] Coenen AML, Kolff M. Body postures in sleep. SleepWake: NSWO (Dutch Society for Sleep-Wake Research); 2011. pp. 44-7.

[4] Verhaert V, Haex B, de Wilde T, Berckmans D, Vandekerckhove M, Verbraecken J, Vander Sloten J. Unobtrusive assessment of motor patterns during sleep based on mattress indentation measurements. IEEE Transactions on Information Technology in Biomedicine. 2011;15(5):787-94.

[5] Califano R, Cecco M, de Cunzo G, Napolitano N, Rega E, Fiorillo I, Naddeo A. School combo-desk comfort assessment: a method for weighting postural factors that affect the overall perceived comfort. Work. 2021;68(S1):S47-S57.

[6] Fiorillo I, Anzisi FJ, Carbone A, Califano R, Naddeo A. A method for postural critical factors checking: the case of library chairs. Work. 2021;68(S1):S87-S100.
[7] Sharafkhani M, Argyle E, Cobb S, Tennent P. Posture, movement, and aircraft passengers: An investigation into factors influencing in-flight discomfort. Work. 2021;68(S1):S183S195.

[8] Smulders M, Naddeo A, Cappetti N, van Grondelle E, Schultheis U, Vink P. Neck posture and muscle activity in a reclined business class aircraft seat watching IFE with and without head support. Applied Ergonomics. 2019;79:25-37.

[9] Torkashvand G, Stephane L, Vink P. Perceived onboard passengers' experience: flight attendants' point of view. Work. 2021;68(S1):S239-S243.

[10] Bouwens J, Hiemstra-van Mastrigt S, Vink P. Ranking of human senses in relation to different in-flight activities contributing to the comfort experience of airplane passengers. International Journal of Aviation, Aeronautics, and Aerospace. 2018;5(2):9.

[11] Nicholson AN, Stone BM. Influence of back angle on the quality of sleep in seats. Ergonomics. 1987;30(7): 1033-41.

[12] Moertl P, Hoefler M, Ewerz B. Incorporating driver activity in holistic comfort models. Work. 2021;68(S1):S119-S128.

[13] Vink P. The sweetness of discomfort: Designing the journey [Inaugural address]. Delft: Delft University of Technology; 2014.

[14] Schifferstein HNJ, Hekkert P. Product experience. Oxford, UK: Elsevier; 2008.

[15] De Looze MP, Kuijt-Evers LF, van Dieen J. Sitting comfort and discomfort and the relationships with objective measures. Ergonomics. 2003;46(10):985-97.

[16] Desmet P, Hekkert P. Framework of product experience. International Journal of Design. 2007;1(1):57-66.

[17] Vink P, Hallbeck S. Comfort and discomfort studies demonstrate the need for a new model. Applied Ergonomics. 2012;43(2):271-6.

[18] Smulders M, Berghman K, Koenraads M, Kane JA, Krishna K, Carter TK, Schultheis U. Comfort and pressure distribution in a human contour shaped aircraft seat (developed with 3D scans of the human body). Work. 2016;54(4): 925-40.

[19] Groenesteijn L, Ellegast RP, Keller K, Krause F, Berger $\mathrm{H}$, de Looze MP. Office task effects on comfort and body dynamics in five dynamic office chairs. Applied Ergonomics. 2012;43(2):320-8.

[20] Groenesteijn L, Hiemstra-van Mastrigt S, Gallais C, Blok M, Kuijt-Evers L, Vink P. Activities, postures and comfort perception of train passengers as input for train seat design. Ergonomics. 2014;57(8):1154-65.

[21] Kamp I, Kilincsoy Ü, Vink P. Chosen postures during specific sitting activities. Ergonomics. 2011;54(11):1029-42.

[22] Ahmadpour N, Kühne M, Robert JM, Vink P. Attitudes towards personal and shared space during the flight. Work. 2016;54(4):981-7.

[23] Kilincsoy Ü. Digitalization of posture-based Seat Design: Developing car interiors by involving user demands and activities [Doctoral Thesis]. Delft: Delft University of Technology; 2019.

[24] Apostolico A, Cappetti N, D’Oria C, Naddeo A, Sestri M. Postural comfort evaluation: experimental identification of Range of Rest Posture for human articular joints. International Journal on Interactive Design and Manufacturing (IJIDeM). 2014;8(2):109-20.

[25] Sammonds GM, Fray M, Mansfield NJ. Effect of long term driving on driver discomfort and its relationship with seat fidgets and movements (SFMs). Applied Ergonomics. 2017;58:119-27. 
[26] Le P, Rose J, Knapik G, Marras WS. Objective classification of vehicle seat discomfort. Ergonomics. 2014;57(4):536-44.

[27] Bouwens JM, Schultheis UW, Hiemstra-van Mastrigt S, Vink P. Expected versus experienced neck comfort. Human Factors and Ergonomics in Manufacturing \& Service Industries. 2018;28(1):29-37.

[28] Hiemstra-van Mastrigt S, Kamp I, Van Veen SAT, Vink P, Bosch T. The influence of active seating on car passengers' perceived comfort and activity levels. Applied Ergonomics. 2015;47:211-9.

[29] Bouwens JM, Fasulo L, Hiemstra-van Mastrigt S, Schultheis UW, Naddeo A, Vink P. Effect of in-seat exercising on comfort perception of airplane passengers. Applied Ergonomics. 2018;73:7-12.

[30] Van Veen S, Orlinskiy V, Franz M, Vink P. Investigating car passenger well-being related to a seat imposing continuous posture variation. Journal of Ergonomics. 2015;4:140.

[31] Franz M, Zenk R, Vink P, Hallbeck S. The effect of a lightweight massage system in a car seat on comfort and electromyogram. Journal of Manipulative and Physiological Therapeutics. 2011;34(2):107-13.

[32] Van Dieën JHL, de Looze MP, Hermans V. Effects of dynamic office chairs on trunk kinematics, trunk extensor EMG and spinal shrinkage. Ergonomics. 2001;44(7):73950.

[33] Van Veen S, Vink P. Can Prior Experience Influence Seating Comfort Ratings? Ergonomics in Design. 2016;24(2):1620.

[34] Roelofsen CPG. Modelling relationships between a comfortable indoor environment, perception and performance change [Doctoral Thesis]. Delft: Delft University of Technology; 2016.

[35] Goossens RHM, Teeuw R, Snijders CJ. Sensitivity for pressure difference on the ischial tuberosity. Ergonomics. 2005;48(7):895-902.
[36] Naddeo A, Cappetti N, Califano R, Vallone M. The role of expectation in comfort perception: the mattresses' evaluation experience. Procedia Manufacturing. 2015;3:4784-91.

[37] Hiemstra-van Mastrigt S, Meyenborg I, Hoogenhout M The influence of activities and duration on comfort and discomfort development in time of aircraft passengers. Work. 2016;54(4):955-61.

[38] Bouwens J, Tsay WJJ, Vink P. The high and low comfort peaks in passengers' flight. Work. 2017;58(4):579-84.

[39] Lewis L, Patel H, Cobb S, D'cruz M, Bues M, Stefani O, Grobler T. Distracting people from sources of discomfort in a simulated aircraft environment. Work. 2016;54(4):963-79.

[40] Vink P, Anjani S, Smulders M, Hiemstra-van Mastrigt S. Comfort and discomfort effects over time: the sweetness of discomfort and the pleasure towards of the end. 1st International Comfort Congress; 2017; Salerno. Salerno.

[41] Sammonds G, Fray M, Mansfield N. Overall car seat discomfort onset during long duration driving trials. Advances in Physical Ergonomics and Human Factors Part II, AHFE Conference Books; 2014.

[42] Ahmadpour N, Lindgaard G, Robert JM, Pownall B. The thematic structure of passenger comfort experience and its relationship to the context features in the aircraft cabin. Ergonomics. 2014;57(6):801-15.

[43] Naddeo A. Towards predicting the (dis)comfort performance by modelling: methods and findings [Doctoral Thesis]. Delft: Delft University of Technology; 2017.

[44] De Lille C, Santema S, Bouwens J, Schultheis U, Vink P. Designing the cabin interior knowing high and low peaks in a passenger flight. AEGATS Conference Paris, abstract nr AEGATS2016_48; 2016. 